\title{
THE INTRODUCTION OF WHITE RHINOCEROS INTO THE MURCHISON FALLS NATIONAL PARK, UGANDA
}

\author{
By John Savidge, Warden
}

\section{INTRODUCTION}

The Northern race of the Square-lipped (White) Rhinoceros (Ceratotherium simum cottoni) occurs in small numbers west of the Albert Nile in Uganda (in the West Nile and West Madi districts) ; in the N.E. Congo (where, at least until June, 1960, it was most numerous in the Garamba National Park); in the S.W. Sudan (in the Nimule National Park and elsewhere), and in Ubangi Shani.

In spite of its imposing dimensions and appearance it is, like all rhino, shy and retiring in temperament, and easily snared or speared. With the black rhino, it is the least observant and the easiest to approach of all big game, with the exception, under certain conditions, of elephant.

Consequently it is fast disappearing from country where formerly it was numerous, like all rhino the world over. Although totally protected (on paper), present-day conditions of roads and the spread of population into once remote areas makes effective protection impossible except in localized areas. For political reasons and because of population pressure it has not been possible to make a national park or other permanent reserve in any of the localities still inhabited by white rhino in Uganda ; and the ratio of game rangers to the rest of the population is one to a million. Rhino horn, which it is still legal to sell at the Mombasa Ivory Room, fetches up to a hundred shillings a pound.

In 1956 the Uganda Game Department and the National Parks began considering the introduction of white rhino into the Murchison Falls National Park. If the experiment were successful the white rhino would have a chance of surviving as a member of Uganda's remarkably diverse fauna.

\section{The Preparations}

As soon as the idea of introducing white rhino to the park had been conceived a barrage of reasons were produced why it would be inadvisable to do so. Scientists rarely make good gamblers, and the ecologists were very properly all caution : 
the white rhino move was a big gamble, with a lot at stake. What little was known of the grassland vegetation of the park did not point to its being as varied as that in the areas where white rhino occur naturally at the present day. On the other hand, an area where they occurred as recently as 1945, before being exterminated by snaring, is separated from one corner of the Murchison Falls National Park by only a few hundred yardsthe width of the Albert Nile. In 1,500 sq. miles of park there might be areas suitable for white rhino even if at first sight the grasslands were different.

This raised another question-should the white rhino be introduced to the section of the park north of the Victoria Nile, into the area already inhabited by the so-called " black" rhino (Diceros bicornis), or should it be released in the less accessible southern section where there are no rhino ? If it were introduced into black rhino country, would the former drive out the white-it is known to be more aggressive. Worse still, supposing the larger white rhino ousted the indigenous black? Put them south of the river and the only area there accessible to a lorry would expose them to the risk of wandering quickly over the western boundary of the park into an area of cultivation between the boundary and Lake Albert, inhabited by a tribe notorious for their handiness in spearing buffalo and hippo. The difficulties seemed unlimited.

The question of black versus white was settled as soon as I met Ian Player, senior ranger of Umfolozi, Natal. He assured me that there the two species live side by side with only occasional friction. When there is a dispute it takes two white rhino to see off one black, in spite of the difference in size.

There remained imponderable questions like the adaptability of white rhino to a change of habitat-although specific in their grazing requirements, they are adaptable in this respect in captivity. Would they reproduce or even stay in one area that was different from anything they had experienced before?

The timing of the experiment was dictated by finance, as unhappily it so often is, but spurred by a fresh wave of rhino poaching in 1960 the question was reopened. It had to be now or never, and arrangements were made for the Kenya big game trappers Randall and $O^{\prime}$ Connell to catch and transport twenty white rhino in December-March, 1961, the dry season.

As the Local District Council in the West Madi area which had been selected for catching the white rhino had been encouraged to take an interest in conserving them on the grounds that the rhino would bring money to the district indirectly from tourism 
and directly, at times, from the sale of animals to zoos, the request to remove some to a national park outside the district had to be backed by an offer of a lump sum in compensation. $£ 50$ an animal was agreed upon, and the total of $£ 1,000$ was provided by Anglia Television, who in return received the filming rights for the whole operation. At last the stage was set.

Ken Randall and Pat O'Connell work from a $30 \mathrm{cwt}$. Ford truck which has to go anywhere that a rhino can go, which is saying a lot. A strong rope is made into a big noose and looped over the end of a long bamboo pole, with which the noose is dropped over the animal's head at the right instant. The other end of the rope is made fast to a special bollard on the side of the truck. The driver must get up to the rhino when it is on reasonably clear ground, even though a moment or two before it may have been running through thick bush or 12-ft. grass, with rough ground, tree stumps, holes, wallows and termite hills to add variety to the obstacles. A rhino moving at its fastest does not exceed 25 m.p.h., but this seems very fast when the truck must accelerate up to $40 \mathrm{~m}$.p.h. through thick bush to overtake. However, an adult white rhino may weigh up to 4,500 pounds and does not like moving fast. The bigger animals at least seem reluctant to break into a gallop from their usual cart-horse like trot. Ken Randall will not tire an animal down by pursuing it for long distances, as this may result in its dying of the after-effects ; the rhino is usually caught within 300 yards of being sighted.

The vehicle draws alongside the rhino as soon as the ground presents a chance and the noose is dropped over the rhino's head : sometimes the running animal may be leaning against the vehicle at this moment. The truck is slowed to tighten the rope gradually and the animal is played to a standstill. The head-rope is taken up around the two bollards on the side of the truck next the rhino and men drop down to the ground to get lighter nylon ropes up over the rhino's feet. The truck has to take whatever punishment the particular rhino hands out. They vary individually, but white rhino are not such hard fighters as black, and are less accurate with their horn when ramming. There are no doors, lamps, mudguards or other breakable fittings on the truck, and no fenders, padding or safety-rails. The people in the open body of the truck have to be both agile and alert-not infrequently someone is thrown out when the truck "leaps" an obstacle encountered at speed in the bush. A passenger has even been known to overtake the truck and 
climb in again when thrown out while the truck was being pursued by an angry rhino! Once the rhino's legs are roped it is all over bar shouting - and a good deal of digging, pulling and pushing. The rhino does the shouting in a voice that is a shrill, squealing whine, of great variety in tone. A calf nearly breaks your heart with its pathetic calls for help, which are mixed with defensive puffs of fear and threat, made by air being forced in and out through the flared nostrils. Everyone else does the digging, the pulling and the pushing. White rhinos sweat along folds in the skin on the limbs, neck, and behind the ears, but not on the body.

Once the animal has been thrown and its legs tied together, it requires little effort to keep its feet up and so to prevent it from trying to stand. Sacks filled with grass are placed under the head, otherwise it may become badly cut and bruised from constantly tossing and thrashing about. In contrast to the figure of speech, rhino have a tender skin which cuts very easily. Calves up to two years old can be man-handled on to the lorry which transports the captured rhino back to the holding stockade, but anything larger has to be eased up twin sets of metal rollers, which necessitates digging holes for the back wheels of the lorry in order to bring the lorry tail-board almost down to ground level.

The holding stockade or "boma" is made large enough for an adult animal just to turn around in, and is constructed of vertical poles entrenched side by side and lashed with crossmembers. Here the ropes are quietly removed. The animal is usually tired of fighting by this time, and has to be informed that it is free of the ropes with a gentle kick from the last person up the "boma " wall. The rhino takes the hint and is on its feet instantly. It then tries the " boma" fence with its horn and some even attempt to climb the fence, standing on their hind legs and reaching quite 10 feet-a formidable sight.

When the animal has cooled down it is offered water, but it generally refuses food for two days or so. As soon as the rhino stops being too wild and rampageous it is tempted with water into the travelling crate. This may take a number of hours of patience to achieve, often at night, when rhino are more active than in the heat of the day. Some rhino are quiet enough to be crated within two days of capture, others may take a week. Once in the crate on the travelling lorry the rhino lies down for most of the journey. The driver can tell when a big animal stands up in its crate because the body of the lorry sways until it lies down again. 


\section{A Release in the Park}

While the catching operation had been getting under way in the Gangu swamp, we in the park had been bridging two rivers and making ten miles of forgotten track passable to the 7 -ton lorry that was to deliver the rhino, as well as cutting a further twelve miles of track to the release area beside the Nile. There we built an off-loading ramp down which the rhino would walk from its crate on the lorry. The ramp was sited in a clearing in the bush near a solid but climbable tree, a couple of hundred yards from the bank of the Nile.

A bare nine days after the trappers had passed through the Park on their way north to Madi, lorries piled high with ropes, bamboo poles, fuel, camping kit and provisions, I received a signal to say that the first two rhino were ready to be delivered. I shall never forget the excitement of my first view of those rhino. I had driven up to Lomunga the best part of 200 miles, the last leg by night through strange country. The rhinocatchers, with true East African hospitality, turned out of bed to welcome me. Ken Randall took me over to the "boma" 30 yards from the camp and shone his torch between the bush poles of the "boma" wall. Inside, a large rhino cow with a magnificent 3-foot horn lay peacefully side by side with her young bull calf, who sucked milk and sang to himself a singsong whine of consolation.

In the Park a week later the cow was released from her crate, and backed cautiously out on to the ramp, her tail curled up tight in excitement like a pig's. Slowly she descended on to level ground and sniffed around the lorry, then stood under the shade of the photographer's escape-tree. When she walked away into the bush for 50 yards the calf was off-loaded, and he circled the ramp and the lorry as the cow had done. Then he started to call, with a husky, whispered "hummer", not unlike the greeting "whicker" of a horse. The cow, trumpet-like ears swivelling in expectation, heard and replied. They walked towards each other and then moved away together towards the river, the cow leading and the calf trotting to keep up. They might have been used to such a reunion every day, it all went so smoothly. This was just the beginning of their lives in a new and strange environment, and of the experiment as a whole. As they disappeared into the bush they took with them the hopes and good wishes of the half-dozen people who witnessed their release. The success of the experiment, or otherwise, was now with them. 


\section{Conclusion}

Thirty-nine days passed before these animals were seen again. They had moved 10 miles from the release area, driven, by the shortage of grass at the end of a long and severe dry season, and later by an invasion of " army worm " that razed the grass almost to bare ground, to seek fresh grazing. They were in good condition and have since been seen a number of times, wandering over about a hundred square miles of the park.

In the month of March before the rains temporarily halted the operation, a total of ten white rhino were released in the park. Two of these, both adult cows, died, probably from the after-effects of bruising during capture. One did not survive more than a day after release. The other had been lame and off-colour when delivered, and as she had a two-year-old female calf at heel, permanent guards were put to watch cow and calf. For three days her condition deteriorated and then she died. The calf was captured and is now being reared at Paraa (the headquarters of the park).

Of the other seven, at the time of writing three have not been seen again. In the absence of any evidence to the contrary eight altogether are believed to be alive and well. The sexes and age groups of the ten animals so far released are : four adult females ; three half-grown males ; one male calf and two female calves. It is hoped to capture a further ten animals for release in the same area. 